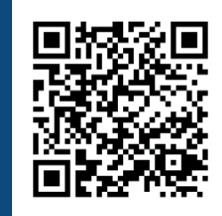

Keywords:

Nanosilica

Limited oxygen index

Thermo gravimetric analysis Scanning electron microscope (SEM)

Received 19/06/2017 Accepted 19/02/2018

Correspondence: mjd-kia59@iauc.ac.ir

Majid Kiaei $^{++}$, Hashem Amiri' ${ }^{2}$, Ahmad Samariha ${ }^{3}$, Naghme Amani ${ }^{4}$

\title{
EFFECT OF NANOSILICA ON THERMAL, FLAMMABILITY, AND MORPHOLOGICALPROPERTIES OF WF/RPS-BASED NANOCOMPOSITES
}

KIAEI, M.; AMIRI, H.; SAMARIHA, A.; AMANI, N. Effect of nanosilica on thermal, flammability, and morphological properties of WF/rPS-based nanocomposites. CERNE, v. 24, n. I, p. 59-66, 2018.

\section{HIGHLIGHTS}

The results showed that the addition of nanosilica increased the thermal stability of the nanocomposite.

It was determined that increasing of nano particles to more than a determined level reduced the Limited oxigen index and flammability.

The data from thermo gravimetric analysis (TGA) indicated the nanosilica greatly enhanced the thermal stability.

\section{ABSTRACT}

The present study considered the effect of nanosilica levels on the thermal, flammability, and morphological properties of nanocomposites made of wood flour and recycled polystyrene. To do so, the recycled polystyrene (50\%), wood flour (50\%), nanosilica (four levels of nanosilica; 0, 2, 4 and 6 phc (parts per hundred compounds)), and maleic anhydride, grafted with polypropylene (at a constant level of 3 phc) were mixed by a twin-screw extruder; then standard experimental samples were made using a hand pressing method. Next, the thermal and flammability properties were measured. The results showed that increasing of nanosilica content to 6 phc by weight increased thermogravimetric analysis (TGA) of nanocomposites; in addition, the limited oxygen index increased. Moreover, scanning electron microscopy (SEM) indicated that an increasing of nanosilica increased compatibility so that better link and adherence was observed among the fiber and matrix material.

' Chalous Branch, Islamic Azad University, Chalous, Iran

${ }^{2}$ Chalous Branch, Islamic Azad University, Chalous, Iran

${ }^{4}$ Young Researchers and Elites Club, Chalous Branch, Islamic Azad University, Chalous, Iran 


\section{INTRODUCTION}

One way to prevent deforestation and resolve the deficiency of lignocellulosic products is the wide use of alternative cellulose resources. Using wood factory wastes is one of the alternative cellulose resources. The wide volume of wastes has been considered as a dilemma and these wooden resources have been wasted, the only way to escape such a dilemma in other cases is by burning them (Winandy et al., 2004; Kiaei et al., 2017a). Wood-plastic composites are modern construction and engineering materials, which have drawn attention. Production and consumption of these products are increasing quickly across the world. The main superiority of these products is the reduction of pressure to forests because they are not dependent on forest resources and solid wood. In most of the applications, these products have similar or even better qualities than wood. These composites are made of the mixture of fibers, wood particles and other lignocellulosic materials, such as wheat stalks and straw, canola, rice, and melted jute with thermoplastic polymers (plastic) (Klyosov, 2006; Ismaeilimoghadam et al., 2016). Wood fiber plastic composites (WFPC) are mixtures of polymer and cellulose materials (Samariha et al., 2013; Kiaei et al., 20 I7a; Kiaei et al., 20I7b). The addition of fibers and natural fillers to reduce costs in the plastic industry and sometimes increase the production have drawn attention after relatively increased plastic costs in previous years. With the use of nano materials, the properties of existing composites in this industry can be improved and various products can be made more efficiently and have a higher added value. One of the nano fillers is nanosilica; using these mineral and organic materials in the production of natural fibers composites can improve some properties, such as strength against fungi and bacteria, flammability, conductivity properties, permeability, thermal and mechanical properties (Han et al., 2008; Kiaei et al., 2014). As nanosilica has a crystalline structure and can create pores, it can increase WPC's durability against ignition and reduce the composites' flammability.

Ismaeilimoghadam et al., (2015) considered the effect of nanosilica on the properties of polypropylene/ wood flour nanocomposites. Their results indicated that with an increasing of nanosilica to $3 \%$, the composites' mechanical features increased and an increasing of the nano particles level to $5 \%$ reduced these features. The SEM morphological results indicated a proper dispersion of nanosilica at the $3 \%$ level, but at $5 \%$ nanosilica the particles accumulated.
Deka and Maji (20I2) considered the effect of nano clay and silica on the properties of WPCs, they reported that increasing of nano particles to $3 \%$ improved the thermal properties of these composites, but the addition of more nano particles to $5 \%$ also reduced these features.

Several researchers have considered the morphology and thermal features of polyethylene terephthalate nanocomposites containing 3 types of nanosilica as melted fillers. The results showed that addition of nanosilica particles to these composites increased the modulus and tensile strengths of the composites, while the elongation at break point was reduced by the addition of nanosilica. Moreover, the results of differential scanning calorimetry (DSC) showed that the nanosilica particles act as a nucleating agent in the growth of crystals and increase the crystallization and strength of composites (Parvinzadeh et al., 20l2).

Jeziorska et al., (20I2) reported that the addition of silica can improve the bond between heavy polyethylene and wood fibers; and that adding nanosilica increased the crystallinity and thermal stability.

Golebiewski and Galeski (2007) studied the thermal stability of polymer composites, which are based on polypropylene, nanoclay, and also polymer based on polypropylene-nanoclay by the means of DSC and TGA. The results of their study showed that the amount of oxygen permeation to the composite reduced significantly when nanoclay was used. By increasing nanoclay the thermal destruction in polymer composite reduced significantly due to reducing of diffusion oxygen and exit of gases and exclusion of volatile gases decomposition (thermal stability improvement).

The main purpose of the present study considers the effect of nanosilica levels on the thermal, flammability, and morphological properties of nanocomposites made of wood flour and recycled polystyrene.

\section{MATERIALS AND METHODS}

\section{Populus wood}

Populus wood flour was prepared as a booster from Arya cellulose Co. (Tehran, Iran). After it was transferred to the laboratory, for uniformity of particle size and to achieve the required size classification, and was shaken by a vibration sieve shaker. Some flour passed through a 60-mesh filter and the rest passed through 80mesh. Then samples were oven-dried for $24 \mathrm{~h}$ at $100{ }^{\circ} \mathrm{C}$ $\pm 3{ }^{\circ} \mathrm{C}$. Polystyrene was prepared with the density of $1.07 \mathrm{~g} \cdot \mathrm{cm}^{-3}$ and a melt flow index of $18 \mathrm{~g} / 10 \mathrm{~min}$ from the 
Tabriz petro chemistry Industry Company (Tabriz, Iran). The raw polystyrene was poured in the extruder under $180{ }^{\circ} \mathrm{C}$ and a motor race of $100 \mathrm{r} \cdot \mathrm{min}^{-1}$; once removed from the extruder the samples were transformed to granule by a mill. The maleic anhydride polypropylene (MAPP) made in Kimia Javid Co. (Isfahan, Iran) with a melt flow index of $\mathrm{I} I$ and $\mathrm{I} . \mathrm{I} \%$ and the joint maleic anhydride (Kimia Javid Co., Isfahan, Iran) were used as the coupling agent for improving the adherence between non-polar polystyrene and the polar wood fiber. Nanosilica powder made by Degussa Co. (Essen, Germany) was used. The characteristics of nanosilica are shown in Table I.

TABLE I Characteristics of nanosilica.

\begin{tabular}{|c|c|c|}
\hline \multicolumn{2}{|l|}{ Silicon Oxide } & $\mathrm{SiO}_{2}$ \\
\hline \multicolumn{2}{|l|}{ Purity } & $99+\%$ \\
\hline \multicolumn{2}{|c|}{ Average Particle Size (APS) (nm) } & 11 to 13 \\
\hline \multicolumn{2}{|c|}{ Specific Surface Area (SSA) } & $200 \mathrm{~m}^{2} \cdot \mathrm{g}^{-1}$ \\
\hline \multicolumn{2}{|c|}{ Bulk Density } & $<0.10 \mathrm{~g} \cdot \mathrm{cm}^{-3}$ \\
\hline \multicolumn{2}{|l|}{ Color } & White \\
\hline \multicolumn{2}{|l|}{ Moisture } & $<2 \%$ \\
\hline \multicolumn{2}{|c|}{ Weight Loss on Ignition } & $30 \%$ \\
\hline \multirow{5}{*}{$\begin{array}{l}\text { Certificate } \\
\text { of Analysis }\end{array}$} & $\mathrm{SiO}_{2}$ & $<99 \%$ \\
\hline & $\mathrm{Ti}$ & $<120 \mathrm{ppm}$ \\
\hline & $\mathrm{Ca}$ & $<70$ ppm \\
\hline & $\mathrm{Na}$ & $<50 \mathrm{ppm}$ \\
\hline & $\mathrm{Fe}$ & $<20$ ppm \\
\hline
\end{tabular}

*Note: According to the producer information

\section{Methods}

To consider the effect of nanosilica on the properties of hybrid composites of wood flour-polystyrene-nanosilica, populus wood flour was used at a constant level of $50 \%$ of the composite weight. The coupling agent content of polypropylene jointed with maleic anhydride (MAPP) was considered at the constant level of 3 phc. In addition, to consider the effect of nanosilica on the properties of hybrid composites of wood flour- polystyrene-nanosilica, nanosilica was used at 4 levels of (0, 2, 4 and 6 phc). Populus wood flour, polystyrene granule, and the coupling agent MAPP were first mixed by a hand blender and then poured into the feed hopper of the extruder; the device was adjusted for all four mixing processes based on conditions that are written in Table 2.

The mixture of polystyrene, populus flour, nanosilica filler, and coupling agent was done at determined weight ratios by a blender device using the twin-Screw extruder model by GMBH made in Dr. Collien, Germany, in which the direction of its screws were contrary to each other. The mixing was done at the Iran Polymer and Petro Chemistry Institute. The polystyrene was passed twice through a twin-screw extruder at $160^{\circ} \mathrm{C}$ and $70 \mathrm{rpm}$.
TABLE 2 The percentages of composite's components at different treatments.

\begin{tabular}{ccccc}
\hline Sample Code & $\begin{array}{c}\text { Poplar Flour } \\
\text { (wt. \%) }\end{array}$ & $\begin{array}{c}\text { Recycled } \\
\text { Polystyrene } \\
\text { (wt. \%) }\end{array}$ & $\begin{array}{c}\text { Nanosilica } \\
\text { (phc*) }\end{array}$ & $\begin{array}{c}\text { Coupling } \\
\text { Agent } \\
\text { (phc) }\end{array}$ \\
\hline $\mathrm{WF} / \mathrm{rPS} / \mathrm{M}$ & 50 & 50 & 0 & 3 \\
$\mathrm{WF} / \mathrm{rPS} / \mathrm{M} / \mathrm{NSiO}_{2}$ & 50 & 50 & 2 & 3 \\
$\mathrm{WF} / \mathrm{rPS} / \mathrm{M} / 4 \mathrm{NSiO}_{2}$ & 50 & 50 & 4 & 3 \\
$\mathrm{WF} / \mathrm{rPS} / \mathrm{M} / 6 \mathrm{NSiO}_{2}$ & 50 & 50 & 6 & 3 \\
\hline
\end{tabular}

rPS: recycled Polystyrene; WF: Poplar Flour; M: MAPP; $\mathrm{NSiO}_{2}$ : Nanosilica; *Parts by weight per hundred parts of compounds

Preparation of materials for making standard experimental samples

After mixing materials, the material left twin to strew extruder got cool. After the materials were cooled and hardened they were made into granular form to be used in injection molding via the WIESER, WGLS 200/200 model (Hamburg, Germany), which is a semiindustrial device located at the Iran Petro Chemistry and Polymer Institute (Tehran, Iran). To eliminate moisture from the granules and prepare them for the injection operation, the granules were put in the oven for $24 \mathrm{~h}$ under approximately $65^{\circ} \mathrm{C}$.

\section{Making standard experimental samples}

To make the samples prepped for Limited oxygen index (LOI), TGA, and SEM, the press machine model WCH made by Toyoseiki Company (Tokyo, Japan) that was located in the Iran Petro Chemistry and Polymer Institute was used. The samples were made under $200{ }^{\circ} \mathrm{C}$ for $4 \mathrm{~min}$ and the pressure of $25 \mathrm{MPa}$. Then, the boards were cooled at $80{ }^{\circ} \mathrm{C}$ for $10 \mathrm{~min}$; during the cooling process, the pressure was maintained.

\section{Morphological analysis by SEM}

Scanning electron microscope (SEM) model AIS2100 Seron Technology, Gyeonggi-do, Korea was used. Samples were first frozen in liquid nitrogen and fractured to ensure that the microstructure remained clean and intact, and ten coated with a gold layer to provide electrical conductivity.

\section{Thermogravimetric analysis (TGA)}

For doing this experiments, the samples prepared by $5-7 \mathrm{mg}$ weight, that were tested by TGA (TGA device model Pyris I made by Perkin Elmer Co., (Santa Clara, USA). This test was performed in the vicinity of $\mathrm{N}$ gas to prevent the materials' oxidation. The samples were heated from $25{ }^{\circ} \mathrm{C}$ to $800{ }^{\circ} \mathrm{C}$ with the rate of $15{ }^{\circ} \mathrm{C} /$ 
min. The mass loss of the samples during the heating process was recorded and calculated. This experiment was conducted using a device at the Iran petro chemistry and polymer institute (Tehran, Iran).

Limited oxygen index (LOI) test

Limited oxygen index (LOI) measurement were carried out using a FTA flammability unit, (Stanton Redcroft S/N710, Epsom, England) according to the ASTM D-2863-I3 (2013) standard. In this method the minimum concentration of oxygen in an oxygen/nitrogen mixture required to support a flaming burn of test specimens were recorded. Sample dimensions were of $15 \mathrm{~mm}$ long, $10 \mathrm{~mm}$ wide, and $2 \mathrm{~mm}$ thick. During the test, a certain volumetric concentration of the specimen was ignited in a tube by holding a hydrogen flame on top of the sample and gradually varying the oxygen and nitrogen gas concentration at fixed rates.

\section{RESULTS AND DISCUSSION}

\section{Thermogravimetric analysis}

Table 3 shows the initial degradation temperature $\left(T_{1}\right)$, the maximum pyrolysis temperature $\left(T_{M}\right)$, the temperature of degradation in various percentages of weight loss $\left(T_{D}\right)$, and the remaining weight (RW\%).

The results of mass loss at four levels of nanosilica by TGA curve are shown in Figure I. As shown in Figure $\mathrm{I}$, the temperature degradation curve of nano-composite was divided into two stages, the first stage was related to the analysis of wooden fibers and the second stage was related to polymer analysis. Therefore, the addition of lignocellulose compounds to polystyrene decreased thermal stability. In fact, at the beginning of the second stage, the analysis temperature transferred to the higher temperature. The addition of nanosilica also reduced degradation of the first stage and produced more remained char. The analysis temperature of the second stage transferred to the higher temperature, and actually the nanosilica increased thermal stability (Table 3).

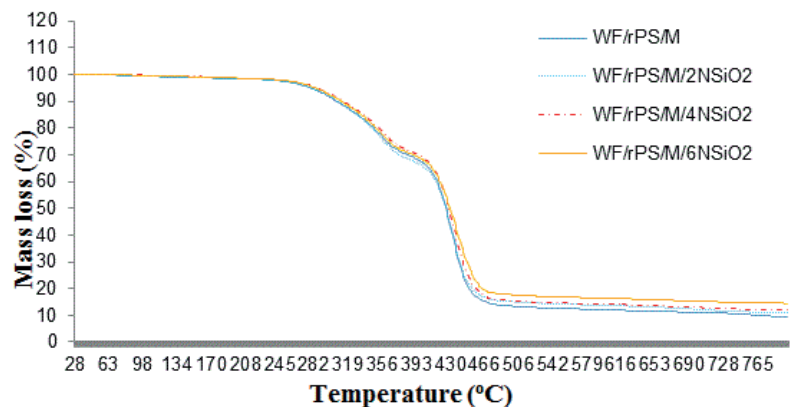

FIGURE I TGA curves of composites with 50 wt.\% WF and 0, 2, 4 and 6 phe nanosilica.
The results showed that an increasing of nanosilica increased thermal stability of the samples; the more nanosilica, the more temperature that was needed for degradation of the nanocomposite, i.e. the sample's weight dropped at a higher temperature. This probably occurred because some compounds that were used in nanoparticles were released and more char was the result of mineral compounds of nanoparticles (Nemati et al., 2016). This finding is in line with the results of previous studies (Wilkie, 2002; Zhu et al., 2002; Gilman et al., 2006). In fact, the nanosilica content's effect for improving thermal stability was due to some conditions, such as polymer type, nanosilica type, and processing conditions. The most important factor in thermal stability, which has been produced by nano particles, is the forming of a char layer that is non-burning; ultimately, the high specific surface area and proper coverage of the char layer affects thermal stability (Khosravian, 2010). Moreover, an increasing of thermal stability may be the result of an increasing of interaction between the polymer matrix, wood flour, and nanosilica (Katsikis et al., 2007). Under the effect of the addition of mineral material, the motion of the polymer chain reduced. The reason of such phenomenon and less motion is proper interaction between polymer and nano particles (Khosravian, 2010). Thermal degradation starts with the formation of free radicals, these free radicals stimulate degradation processes of the polymer chain. The degradation level of the polymer chain is related to free radicals motion from a chain to other and itemized motion through polymer chains; the effect of the chains motion reduced and thermal stability increased due to the presence of nano particles. Therefore, degradation occurs in higher temperatures (Luyt et al., 2009). Besides the protective structures that nanosilica produces against heat (e.g. char layer), other mechanisms have been suggested for reducing flammability. Based on the obtained information, the suggested mechanism for reducing flammability was based on polymer pyrolysis and the collapse of nanocomposite structure for creating the carbonaceoussilica barrier. This polymer barrier protects the intact undercoat layer against heat and slows fuel evaporation (Gilman et al., 2000; Kashiwagi et al., 2004). Deka and Maji (2012) observed that thermal stability of polymer compounds increased after the addition of coupling agent and wood flour. The initial temperature also increased after addition of nanosilica and clay. The diffusivity coefficient of nanosilica particles improved heat diffusion throughout the composite; this postponed surface ignition and the diffusion of volatile combustible particles that were produced across 
TABLE 3 Thermal Analysis and Limited Oxygen Index of WPC and Nanosilica.

\begin{tabular}{|c|c|c|c|c|c|c|c|c|c|c|}
\hline \multirow[t]{2}{*}{ No. } & \multirow[t]{2}{*}{ Treatment Code } & \multirow{2}{*}{$\begin{array}{c}\mathrm{TI} \\
\left({ }^{\circ} \mathrm{C}\right)\end{array}$} & \multirow{2}{*}{$\begin{array}{l}\mathrm{TM} \\
\left({ }^{\circ} \mathrm{C}\right)\end{array}$} & \multirow{2}{*}{$\begin{array}{l}\text { TF } \\
\left({ }^{\circ} \mathrm{C}\right)\end{array}$} & \multicolumn{4}{|c|}{$\begin{array}{c}\text { Temperature of Decomposition (TD) in }{ }^{\circ} \mathrm{C} \text { at } \\
\text { Different Weight Loss (\%) Values }\end{array}$} & \multirow{2}{*}{$\begin{array}{l}\text { RW\% at } \\
600^{\circ} \mathrm{C}\end{array}$} & \multirow[t]{2}{*}{ LOI (\%) } \\
\hline & & & & & $80 \%$ & $60 \%$ & $40 \%$ & $20 \%$ & & \\
\hline 1 & WF/rPS/M & 19 & 9.26 & 456 & 438 & 421 & 352 & 505 & 390 & 222 \\
\hline 2 & WF/rPS/M/2NSiO2 & 19.11 & 10.96 & 460 & 438 & 420 & 350 & 497 & 390 & 224 \\
\hline 3 & WF/rPS/M/4NSiO2 & 19.21 & 11.79 & 463 & 441 & 425 & 357 & 501 & 392 & 228 \\
\hline 4 & WF/rPS/M/6NSiO2 & 19.6 & 14.43 & 470 & 444 & 424 & 354 & 504 & 390 & 224 \\
\hline
\end{tabular}

TI- temperature corresponding to the beginning of the decomposition

TM- temperature corresponding to the maximum rate of mass loss

TF- temperature corresponding to the ending of the decomposition

RW- remaining weight

the composite. The addition of the nanosilica increased the polymethyl methacrylate (PMMA) thermal stability as well.

\section{Flammability Treatment}

The limited oxygen index data determined that the higher the nanosilica content, the higher the LOI; i.e. the sample needed more oxygen for ignition by the addition of more nanosilica by adding more nanosilica, the sample needed more oxygen for ignition. Moreover, increasing of nanosilica reduced samples' flammability and ignition occurred harder. The use of nano-silica in the improvement of the thermal properties and reduction of flammability was one of the confirmed issues. It was observed that an increasing of nanosilica increased the LOI level with improved adherence on the intersection part of the polymer and wood. Higher levels of LOI may have been the result of the creation of carbonaceoussilica char on the surface. The silica level increases as the creation of char would increase. The char produced tiny and black smokes that had a flame similar to a candle flame. Generally, the amount of absorbed oxygen that led to the flammability process was related to some factors, such as oxygen pressure, temperature, and specific surface area of that material that was in contact with oxygen. Objects with a high surface area (porous bodies, sponges, and powder) can absorb more oxygen; therefore, these materials are more prone to fire. Nanosilica can act as a barrier to prevent permeation and the motion of oxygen to the structure of the nanocomposite; in fact, it acts as a barrier against gasses and fills the pores (Nemati et al., 2016).

Composites mostly have pores and these pores have relations with each other. Oxygen typically passes from these pores and increases the process of flammability, but the presence of nano particles interrupt this process by filling the pores and reducing ignition and thermal stability (Khosravian, 2010). In fact, the tortuous path that is produced by nanosilica is a barrier for oxygen that postpones the capacity of ignition. The addition of modified silica with CTAB increases the interaction between wood, clay, and polymer through hydroxyl and cetyl groups. Silica nano particles are also the thermal barrier of oxygen that improves its flame dilatory property. ERDEM et al., (2009) also reported the improvement of the flame dilatory property with the addition of nanosilica.

There is belief that the barrier effect of nanosilica, which slows the permeation of oxygen into the sample, causes the degradation of nanocomposites to occur at higher temperatures (Gilman et al., 2006). The results showed that the addition of nanosilica increased the thermal stability of the nanocomposite. The most important factor in increasing thermal stability, which is produced by nano particles, is the creation of a nonburning char layer. This layer has a high specific surface area and proper coverage, and it can affect the thermal stability significantly (Khosravian, 2010). Meanwhile, the presence of nanosilica may prevent the release and movement of volatile and flammable gases, as well as movement from inside the composite towards the surface (Burnside: Giannelis, 1995; Nemati et al., 2016).

In previous studies, it was determined that increasing of nano particles to more than a determined level reduced the LOI and flammability. An over increase of nanosilica increases oxidation and inverts thermal stability (Khosravian, 2010). Furthermore, the pores have been increased via the effect of the accumulation of nano particles in composites; therefore, the required space for the entrance of oxygen, provided flammability behavior, and thermal stability decreases (Klyosov, 2007). The materials that slow and postpone ignition should be used with a higher loading level. The higher loading level of these retardants usually leads to a high density and inflexibility of the final product; in addition, it can produce some problems in blending and extrusion (Beyer, 2002).

\section{SEM Morphology}

In the present study, SEM considered the microstructures of composites that were produced on breakage surfaces. The produced micrographs confirmed the results of the composite thermal tests. The SEM images considered the effect of nanosilica on the intersection of cellulose fiber and polymer matrix. 
The empty spaces indicated weak connection between the fiber and matrix, which meant that the fiber could separate from matrix under pressure and stress. The SEM images showed that compatibility and the connection between the cellulose material and polymer matrix increased by increasing of nanosilica levels.

Therefore, better and stronger joints were created between the matrix and the fibers; this issue can be confirmed by considering the amount of empty spaces and homogeneity of breakage surfaces on the composites (Bazyar and Samariha 2017). In addition, an increased LOI in these samples could also confirm this issue. In the samples containing 6 phc nanosilica, fewer empty spaces were observed, which indicated that the cellulose fibers did not separate from the matrix under stress due to proper commissure with the matrix; therefore they broke along with their matrix.
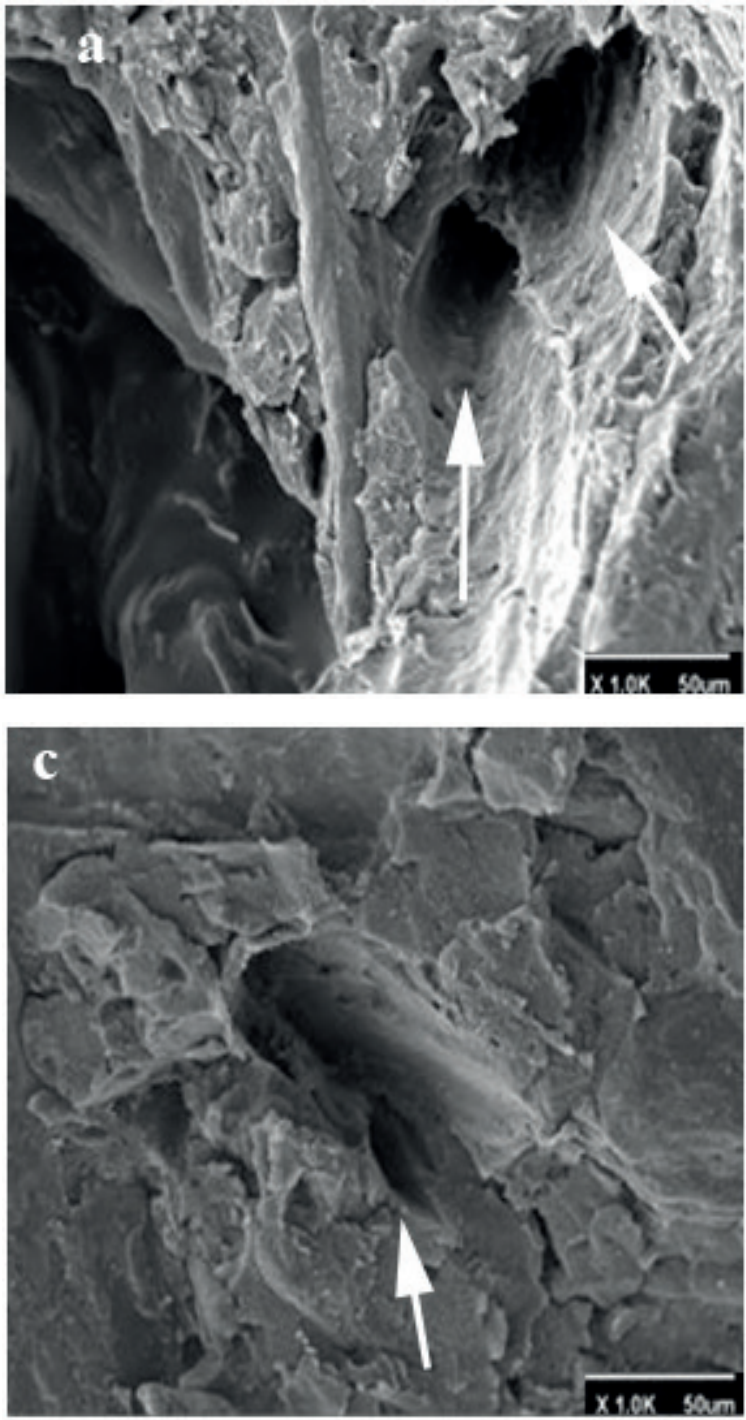

The SEM images illustrated the distribution and compatibility between the fillers and matrix. Figures 2 ( $a$ to $d$ ) show the breakage surfaces of the nanocomposite samples containing $50 \%$ wood flour at 4 levels of nanosilica (0, 2, 4, and $6 \mathrm{phc})$. The empty spaces indicated weak joints between the flour and the matrix. A nanosilica addition increased compatibility, reduced the number of empty pores, and created better adherence between fiber and matrix. However, fewer pores can be observed at a 6 phc level of nanosilica, which indicated very good bond between matrix and fiber.

\section{CONCLUSIONS}

The present study considered the effect of nanosilica on thermal, flammability, and morphological properties of nanocomposites made of populus wood
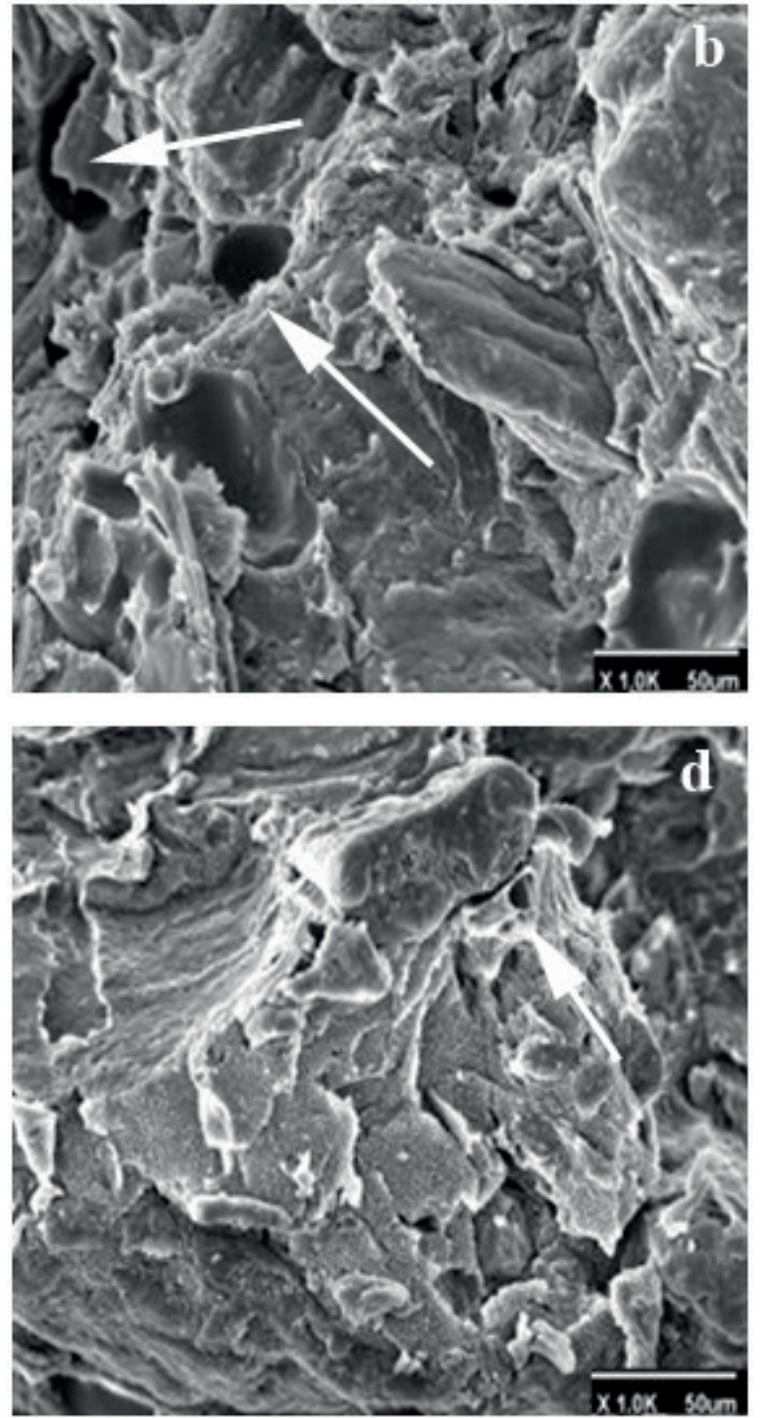

FIGURE 2 SEM image of nanocomposite a) 0 phc, b) 2 phc, c) 4 phc, and d) 6 phc nanosilica. 
flour and recycled polystyrene, and the following results have been obtained:

I. The maximum and minimum values of limited oxygen index (LOI) were found to be $19.60 \%$ and 19\% for the composites filled 6 phc nanosilica and 0phc (control sample).

2. The data from Thermogravimetric analysis (TGA) indicated the nanosilica greatly enhanced the thermal stability. The remaining weight of the recycled polystyrene/poplar flour blends gradually increased with increasing the nanosilica content.

3. Scanning electron microscopy (SEM) indicated that an increasing of nanosilica increased compatibility so that better link and adherence was observed among the fiber and matrix material. Furthermore, fewer pores and empty spaces were observed.

\section{REFERENCES}

ASTM D2863-13 Standard test method for measuring the minimum oxygen concentration to support candlelike combustion of plastics. ASTM International, West Conshohocken, PA. 2013.

BAZYAR, B.; SAMARIHA, A. Thermal, Flammability, and Morphological Properties of Nano-composite from Fir Wood Flour and Polypropylene. BioResources, v. I2, n.3, p. 6665-6678. 2017.

BEYER, G. Nanocomposites: A new class of flame retardants for polymers, Plastics, Additives and Compounding, v. 4, n. 10, p. 22-28. 2002.

BURNSIDE, S. D.; GIANNELIS, E. P. Synthesis and properties of new poly (dimethylsiloxane) nanocomposite, Chemistry of Materials, v. 7, n. 9, p. I597-I600. 1995.

DEKA, B. K.; MAJI, T. K. Effect of SiO2 and nano clay on the properties of wood polymer nanocomposite. Polymer Bulletin, v. 70, n. 2, p. 403-4I7. 2012.

ERDEM, N.; CIRELI, A. A.; ERDOGAN, U. H. Flame retardancy behaviors and structural properties of polypropylene/ nano- $\mathrm{SiO}_{2}$ composite textile filaments. Journal of Applied Polymer Science, v. I I I, n. 4, p. 2085-209I. 2009.

GILMAN, J. W.; JACKSON, C. L.; MORGAN, A. B.; HARRIS, R.; MANIAS, E.; GIANNELIS, E. P.; PHILLIPS, S. H. Flammability properties of polymer- layered-silicate nanocomposites. Polypropylene and polystyrene nanocomposites. Chemistry of Materials, v. 12, n. 7, I866-|873. 2000.

GILMAN, J. W.; HARRIS, R. H.; SHIELDS, J. R.; KASHIWAGI, T.; MORGAN, A. B. A study of the flammability reduction mechanism of polystyrene-layered silicate nanocomposite: Layered silicate reinforced carbonaceous char. Polymers for Advanced Technologies, v. 17, n. 4, p. 263-27I. 2006.
GOLEBIEWSKI, J.; GALESKI, A. Thermal stability of nanoclay polypropylene composites by simultaneous DSC and TGA. Composites Science and Technology, v. 67, n. I5, p. 3442-3447. 2007.

HAN, G.; LEI, Y.; WU, Q.; KOJIMA, Y.; SUZUKI, S. Bamboofiber filled high density polyethylene composites: Effect of coupling treatment and nanoclay. Journal of Polymers and the Environment, v. 16, n. 2, p. I23-130. 2008.

ISMAEILIMOGHADAM, S.; SHAMSIAN, M.; KASHKOULI BAYAT, A.; KORD, B. Evaluation of effect of nano Sio2 on the physical, mechanical and morphological properties of hybrid nanocomposite from polypropylene-wood flour. Iranian Journal of Wood and Paper Science Research, v. 30 , n. 2, p. 266-277. 2015.

ISMAEILIMOGHADAM, S.; MASOUDIFAR, M.; NOSRATI, B.; SHAMSIAN, M. Effects of Inorganic Nanoparticles on Mechanical and Morphological Properties of Wood Flour-Polypropylene Nano Composites. Drewno, v. 59, n. 196, p. 127-137. 2016.

JEZIORSKA, R.; ZIELECKA, M.; SZADKOWSKA, A.; WENDA, M.; TOKARZ, L. Wood-filled high density polyethylene composites with nanosilica containing immobilized nanosilver. Polimery, v. 57, n. 3, p. 192-203. 2012.

KATSIKIS, N.; ZAHRADNIK, F; HELMSCHROTT, A.; MÜNSTEDT, H.; VITAL, A. Thermal stability of poly (methyl methacrylate)/silica nano-and microcomposites as investigated by dynamic-mechanical experiments, Polymer Degradation and Stability, v. 92, n. II, p. 1966-1976. 2007.

KASHIWAGI, T.; HARRIS, R. H.; ZHANG, X.; BRIBER, R. M.; CIPRIANO, B. H.; RAGHAVAN, S. R.; SHIELDS, J. R. Flame retardant mechanism of polyamide 6-clay nanocomposites. Polymer, v. 45, n. 3, p. 88I-89I. 2004.

KHOSRAVIAN, B. Studying mechanical, physical, thermal and morphological characteristics of hybrid composites of polypropylene/wood flour/wollastonite. Master's Thesis, University of Tehran, Tehran, Iran. 2010.

KIAEI, M.; KORD, B.; VAYSI, R. Influence of residual lignin content on physical and mechanical properties of kraft pulp/pp composites. Maderas. Ciencia y tecnología, v. 16, n. 4, p 495-503. 2014.

KIAEI, M.; MOGHDAM, Y. R.; KORD, B.; SAMARIHA, A. The effect of Nano-MgO on the mechanical and flammability properties of hybrid nano composites from wood flourpolyethylene. Maderas. Ciencia y tecnología, v. 19, n. 4, p 47I-480. 20I7a.

KIAEI, M.; KORD, B.; SAMARIHA, A.; MOGHDAM, Y. R.; FARSI, M. Mechanical, Flammability, and Morphological Properties of Nano-composite Plastic based on Hardwood Flour High-density Polyethylene Embedding by Nano-Zinc Oxide. BioResources, v. I2, n. 3, p 65I8-6528. 20 I 7b. 
KLYOSOV, A. A. Wood Plastic Composites, John Wiley \& Sons, Inc., New York, USA, 2007. 726p.

LUYT, A. S.; DRAMIĆANIN, M. D.; ANTIĆ, Ž.; DJOKOVIĆ, V. Morphology, mechanical and thermal properties of composites of polypropylene and nanostructured wollastonite filler. Polymer Testing, n. 28, v. 3, p. 348-356. 2009.

NEMATI, M.; ESLAM, H. K.; TALAEIPOUR, M.; BAZYAR, B.; SAMARIHA, A. Effect of nanoclay on flammability behavior and morphology of nanocomposites from wood flour and polystyrene materials. BioResources. v. II, n. I, p. 748758. 2016.

PARVINZADEH, M.; MORADIAN, S.; RASHIDI, A.; YAZDANSHENAS, M. E. Surface characterization of polyethylene terephthalate/silica nanocomposites. Applied Surface Science, v. 256, n. 9, p. 2792-2802. 2010.
SAMARIHA, A.; BASTANI, A.; NEMATI, M.; KIAEI, M.; NOSRATI, H.; FARSI, $M$. Investigation of the mechanical properties of bagasse flour/polypropylene composites. Mechanics of Composite Materials, v. 49, n. 4, p. 447-454. 2013.

WILKIE, C. Recent advanced in fire retardancy of polymerclay nanocomposite. Recent Advances in Flame Retardancy of Polymers, v. I3, p. 206-2 17. 2002.

WINANDY, J. E.; STARK, N. M.; CLEMONS, C. M. Considerations in recycling of wood-plastic composites. in: $5^{\text {th }}$ global wood and natural fiber composites symposium, Kassel, Germany, pp. 27-28. 2004.

ZHU, J.; START, P.; MAURITZ, K. A.; WILKIE, C. A. Siliconmethoxide-modified clays and their polystyrene nanocomposites. Journal of Polymer Science Part APolymer Chemistry, v. 40, n. I0, p. I498-I503. 2002. 